\title{
Development of a PIGE-Detection System for in-situ Inspection and Quality Assurance in the Evolution of Fast Rotating Parts in High Temperature Environment Manufactured from TiAl
}

\author{
S. Neve ${ }^{1^{\star}}$, H.-E. Zschau ${ }^{2}$, P.J. Masset ${ }^{3}$ and M. Schütze ${ }^{2}$ \\ ${ }^{1}$ Institute for Nuclear Physics (IKF), Goethe-University, Max-von-Laue-Str.1, D-60438 Frankfurt, Germany \\ ${ }^{2}$ DECHEMA-Forschungsinstitut, Theodor-Heuss Allee 25, D-60486 Frankfurt, Germany \\ ${ }^{3}$ Fraunhofer-Institut UMSICHT, An der Maxhütte 1, D-92237 Sulzbach-Rosenberg, Germany
}

\section{ARTICLE INFO}

Article history:

Received 01 March 2013

Received in revised form 24 April 2013

Accepted 25 April 2013

Keywords:

Titanium aluminides

High temperature technology

Oxidation protection

Halogen effect

PIGE

\begin{abstract}
A B S T R A C T
Intermetallic $\gamma$-titanium aluminides are a promising material in high temperature technologies. Their high specific strength at temperatures above $700^{\circ} \mathrm{C}$ offers the possibility for their use as components of aerospace and automotive industries. With a specific weight of $50 \%$ of that of the widely used Ni-based superalloys $\mathrm{TiAl}$ is very suitable as material for fast rotating parts like turbine blades in aircraft engines and land based power stations or turbocharger rotors. Thus lower mechanical stresses and a reduced fuel consumption and $\mathrm{CO}_{2}$-emission are expected. To overcome the insufficient oxidation protection the halogen effect offers an innovative way. After surface doping using F-implantation or liquid phase-treatment with an F-containing solution and subsequent oxidation at high temperatures the formation of a protective alumina scale can be achieved. By using non-destructive ion beam analyses (PIGE, RBS) F was found at the metal/oxide interface. For analysis of large scale components a new vacuum chamber at the IKF was installed and became operative. With this prototype of in-situ quality assurance system for the F-doping of manufactured parts from TiAl some performance test measurements were done and presented in this paper.
\end{abstract}

(C) 2013 Atom Indonesia. All rights reserved

\section{INTRODUCTION}

The aerospace industry is seriously interested in the reduction of energy consumption and fuel. Large efforts have been made by using light-weight carbon reinforced plastics (CFRP, CFK) for aeroplanes. Another way is to reduce the weight of fast rotating turbine blades in aircraft engines. Beside the commonly used Ni-based superalloys $\gamma$-titanium aluminides offer the required high specific strength from room-temperature up to $1000^{\circ} \mathrm{C}$ [1,2]. With a specific weight of $3.8 \mathrm{~g} / \mathrm{cm}^{3}$ compared to $8 \mathrm{~g} / \mathrm{cm}^{3}$ of Ni-based superalloys the overall weight of the components could be reduced drastically. Lower moment of inertia would induce lower mechnical stresses and a new light-weight design would become possible. Known issues are the high production costs for components made of $\mathrm{TiAl}[3]$ and their insufficient oxidation resistance at elevated temperatures above $700^{\circ} \mathrm{C}$ [4]. The latter can be overcome by using the innovative halogen effect as was already reported in several papers [5-12]. After doping the surface with F-ions and

\footnotetext{
Corresponding author.

E-mail address: neve@atom.uni-frankfurt.de
}

pre-oxidizing at high temperatures, the formation of a protective alumina scale can be achieved. The effect was proven to work for at least $8760 \mathrm{~h}$ (1 year) [13]. An almost constant F-content located at the metal/oxide interface over long exposure times indicates the formation of an alumina scale due to the halogen effect [6]. In this work turbine blades have been modified by dipping in F-containing liquid as well as spraying with F-containing aerosol. Measurements of segments of the blades were compared to measure of uncut blades in a new analysis chamber. This new vacuum chamber enables non-destructive fluorine depth profiling on large industrial components by means of ion beam analysis which is required for in-situ quality assurance of industrial components.

\section{THEORY}

The halogen effect is based on the preferred formation of gaseous $\mathrm{AlF}_{\mathrm{x}}$ species and their oxidation to $\mathrm{Al}_{2} \mathrm{O}_{3}$ during their outward migration into regions of higher oxygen partial pressure [12]. A certain amount of halogens in a specific depth is necessary to keep the F-partial pressure in a window 
of positive effect, to enhance the formation of $\mathrm{AlF}_{\mathrm{x}}$ species and to not enhance the formation of $\mathrm{TiF}_{\mathrm{x}}$ species [13]. The F-amount depends on Al-concentration of the alloy and oxidation temperature.

For determining the F-content before and after oxidation Particle Induced Gamma-ray Emission (PIGE) was applied and the nuclear resonance ${ }^{19} \mathrm{~F}(\mathrm{p}, \propto \gamma){ }^{16} \mathrm{O}$ was excited with protons at $340 \mathrm{keV}$ and $484 \mathrm{keV}$ which were selected accordingly as the samples were oxidized or not. The maximum analyzable width of a F-profile without deconvolution depends on the energetic difference between the resonances and amounts to approximately $1 \mu \mathrm{m}$.

Table 1. Used resonances and attained depth resolution.

\begin{tabular}{ccc}
\hline & $340 \mathrm{keV}$ & $484 \mathrm{keV}$ \\
\hline Used for & $\begin{array}{c}\text { oxidized samples } \\
\mathrm{Al}_{2} \mathrm{O}_{3} \text {-matrix }\end{array}$ & $\begin{array}{c}\text { non-oxidized } \\
\text { TiAl-matrix }\end{array}$ \\
$\begin{array}{c}\text { Resonance } \\
\text { width } \Gamma[15] \\
\text { Depth } \\
\text { resolution } \\
\begin{array}{c}\text { Normalized } \\
\text { Yield }\end{array}\end{array}$ & $2.4 \mathrm{keV}$ & $0.9 \mathrm{keV}$ \\
\hline
\end{tabular}

The beam spot size was collimated to $2 \times 2 \mathrm{~mm}^{2}$. High energetic gamma rays could be easily registered with a 5 inch NaI detector. In their energy range ( 5 to $7 \mathrm{MeV}$ ) almost no background or interferences to other elements were noticed. Depth resolutions given in Table 1 were depending on resonance widths $\Gamma$, matrix used and experimental setup. Energy straggling caused an increase of depth resolution in larger depths because of resonance broadening. Due to the low background the sensitivity of a measurement in the $\mathrm{Al}_{2} \mathrm{O}_{3}$-matrix was about 0.05 at $\%$ fluorine. F-concentrations in atomic percent have been calculated from the gamma ray yields by comparing them to the reference yield of a $\mathrm{CaF}_{2}$ single crystal (see Fig. 1).

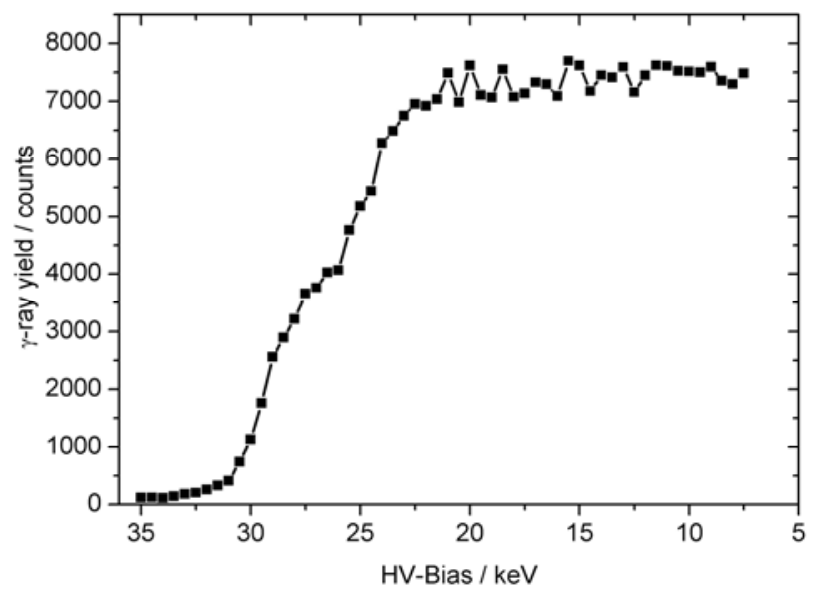

Fig. 1. Reference measurements for PIGE analysis. Excitation curve of the resonance at $340 \mathrm{keV}$ using a $\mathrm{CaF}_{2}$ single crystal coated with Au. Accelerator energy was $370 \mathrm{keV}$.
This was possible since reference and sample have been analyzed with the same number of protons (Q $=1 \mu \mathrm{C} /$ channel). Strict calculation of $c_{F}$ paid attention to stopping powers depending on the F-content itself and resulted in

$$
c_{F} / c_{M}=\frac{Y_{S} \cdot \varepsilon_{M}}{Y_{R} \cdot 3 / 2 \varepsilon_{R}-Y_{S} \cdot \varepsilon_{F}}
$$

where $c_{F}$ and $c_{M}$ were the concentrations of fluorine and the matrix $\mathrm{M}=\mathrm{TiAl}$ or $\mathrm{Al}_{2} \mathrm{O}_{3}, Y_{S}$ and $Y_{R}$ the gamma-ray yields of sample and reference, $\varepsilon$ the stopping power cross sections of $\mathrm{CaF}_{2}-$ reference, fluorine and matrix $\mathrm{M}$.

Accelerator energy was calibrated by means of a $\mathrm{CaF}_{2}$ coated sample. The channel in which resonance energy took place is indicated in Fig. 2.

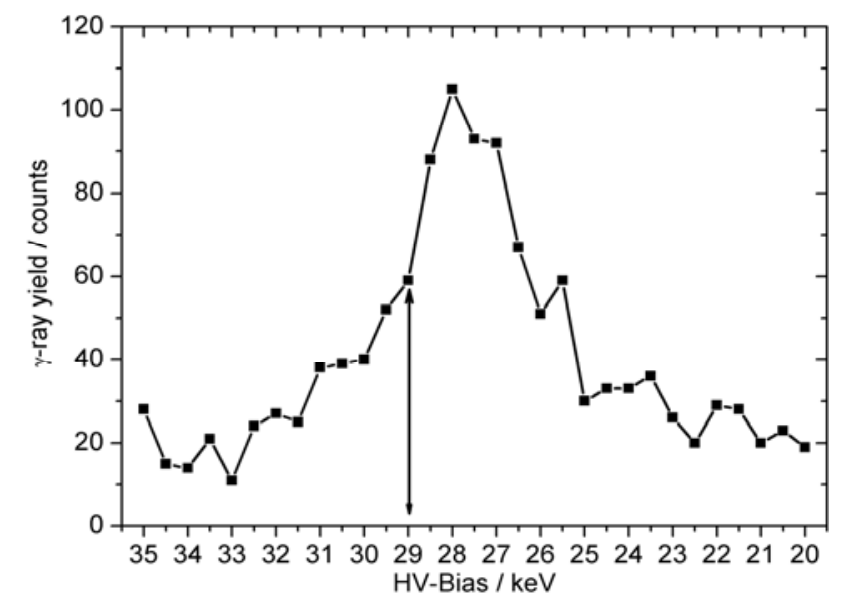

Fig. 2. Reference measurements for PIGE analysis. Calibration of proton energy using a very thin coated sample showing the resonance at $340 \mathrm{keV}$. Accelerator energy was set to $370 \mathrm{keV}$, actual proton energy was found to be $369 \mathrm{keV}$.

The stopping powers used for conversion of proton energy into depth scale were depending on energy and the calculated F-concentration for each depth channel. For calculation of stopping powers of the raw materials TiAl and $\mathrm{Al}_{2} \mathrm{O}_{3}$ with the code SRIM [16] the amount of $\mathrm{Nb}$ and $\mathrm{C}$ in the alloy was neglected. In addition to the PIGE-analysis some RBS-spectra (ㄹutherford Backscattering Spectrometry) have been recorded under $171^{\circ}$ backscattering angle using a $2 \mathrm{MeV} \mathrm{He}^{+}$beam, collimated to $2 \times 2 \mathrm{~mm}^{2}$. The spectra were converted into elemental depth profiles by means of the software SIMNRA [17].

\section{EXPERIMENTAL METHOD}

Whole turbine blades (overall dimensions $6 \mathrm{x}$ $5 \times 4 \mathrm{~cm}^{3}$ ) and smaller segments made from intermetallic TNB-alloy (Ti - (44-46) $\mathrm{Al}$ - (4-8) 
$\mathrm{Nb}-(0-0.2) \mathrm{C})$ have been used as samples. Due to component geometry with convex and concav surfaces dipping in $0.1 \mathrm{wt} \% \mathrm{HF}$ solution and spraying with F-aerosol have been chosen as fluorination methods which are both in principle suitable for complex geometries and proven effective treatments for establishing an alumina scale via the halogen effect [8-10,18]. Residence time in the acid was $60 \mathrm{~min}$. Afterwards the samples were dried in laboratory air.

A reference sample was beamline ion implanted with $2 \times 10{ }^{17}$ F-ions $/ \mathrm{cm}^{2}$ at $20 \mathrm{keV}$ ion energy as described in [6]. In the as received condition the surface of the segments was very rough and covered with a thick grey scale. Since this was probably due to the machining of the specimens using spark erosion technique, a few segments have been polished manually with 1200 grit abrasive paper. The surface of the uncut turbine blade was polished during its fabrication process. The reference sample of dimensions $1 \mathrm{~cm}^{2} \times 3 \mathrm{~mm}$ was polished with 4000 grit $\mathrm{SiC}$ paper.

\section{Conception of analysis chamber}

Figure 3 shows the conception of the measuring chamber. The accelerator supplies the ion beam from the left. First the beam is collimated to $2 \times 2 \mathrm{~mm}^{2}$. Afterwards, a rotating tripod enables in-situ measurement of a fraction of the ion beam current without electrical contact to the sample holder. This is necessary because the insulated sample holder is connected to a high voltage power supply $(-20 \mathrm{kV}$ to $+35 \mathrm{kV})$. By decreasing bias voltage the nuclear resonance is shifted in steps of $0.5 \mathrm{keV}$ inside the sample.

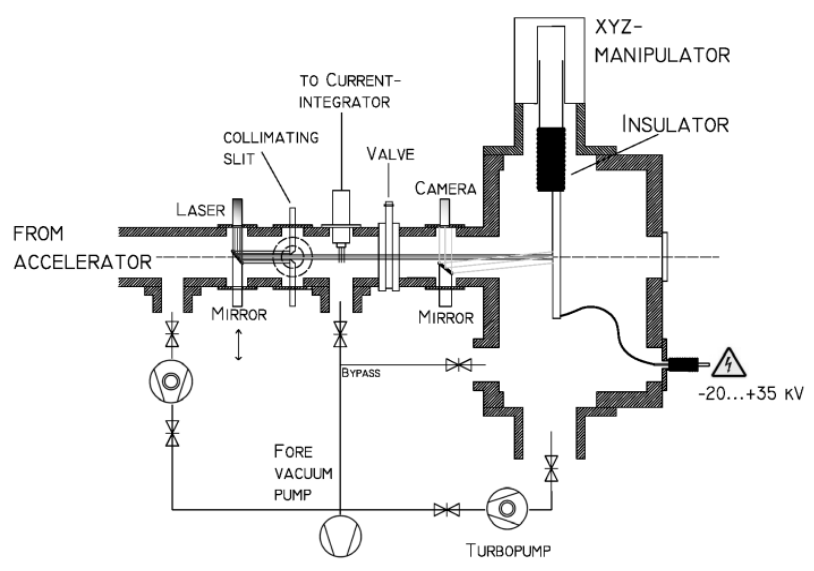

Fig. 3. Drawing of the measuring chamber for the PIGE analysis of industrial components.

The sample holder was especially designed to mount turbine blades and can easily be modified for samples with different geometry. The time requirement for such an analysis is often determined by the number of pumping events to reach a vacuum of $10^{-4} \mathrm{~Pa}$. Three turbine blades and the reference samples can be mounted and measured without breaking the vacuum. It can be moved by $\pm 10 \mathrm{~cm}$ in vertical direction with a motorized xyz-manipulator. This enables easy switching between the samples and the observation of beam shape on the output side quartz window. Thus, the overall pumping time could be reduced significantly. Adjustment in xyplane is $\pm 25 \mathrm{~mm}$. Full control of the analysing beam spot is a requirement of quality assurance. Therefore a laser-camera system was installed. A HeNe-laser beam (5 $\mathrm{mm}$ diameter) can be swivelled via a mirror in place of the ion beam before the collimating slits. The spot size and its location on the sample can be observed using a second mirror and a camera. With this vacuum chamber for the first time non-destructive ion beam analyses on industrial components with large dimensions was achieved.

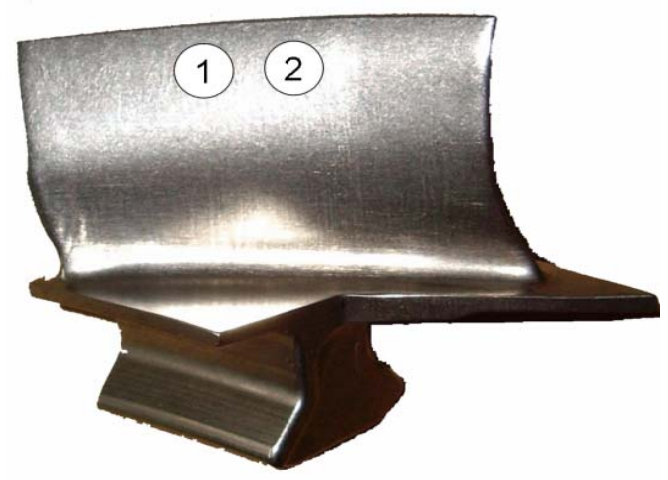

Fig. 4. TiAl-turbine blade with dimensions $6 \times 5 \times 4 \mathrm{~cm}^{3}$. The non-critical beam spot locations 1 and 2 of the measurements in Fig. 5 are indicated.

\section{Quality assurance by means of F-profiling}

The first hours of oxidation were accompanied by huge F-losses since $\mathrm{F}$ outward diffusion was not impeded yet as there was no alumina layer on top at that time. For the beam line implanted sample the maximum F-concentration dropped from 48 at $\%$ to 1.6 at\% during the first 20 hours of oxidation. This means the F-loss in the maximum was about $95 \%$ of its initial value. Once a dense alumina scale is formed the losses are almost suppressed. The stable F-amount indicates a succesful oxidation protection, since this can only occur if the fluorine diffusion outward is inhibited. The oxide scale was examined by RBS-analysis and consisted mainly of alumina. 


\section{RESULTS AND DISCUSSION}

The high temperature oxidation resistance could be improved for all samples and fluorination techniques used. For the TNB alloy both treatments resulted in clearly reduced recorded mass gain of $0.2 \mathrm{mg} / \mathrm{cm}^{2}$ for HF-treatment and $0.4 \mathrm{mg} / \mathrm{cm}^{2}$ for F-aerosol spraying after $120 \mathrm{~h}$ at $900^{\circ} \mathrm{C}$, whereas an untreated sample gained about $1.4 \mathrm{mg} / \mathrm{cm}^{2}$ after $60 \mathrm{~h}$ already [11].

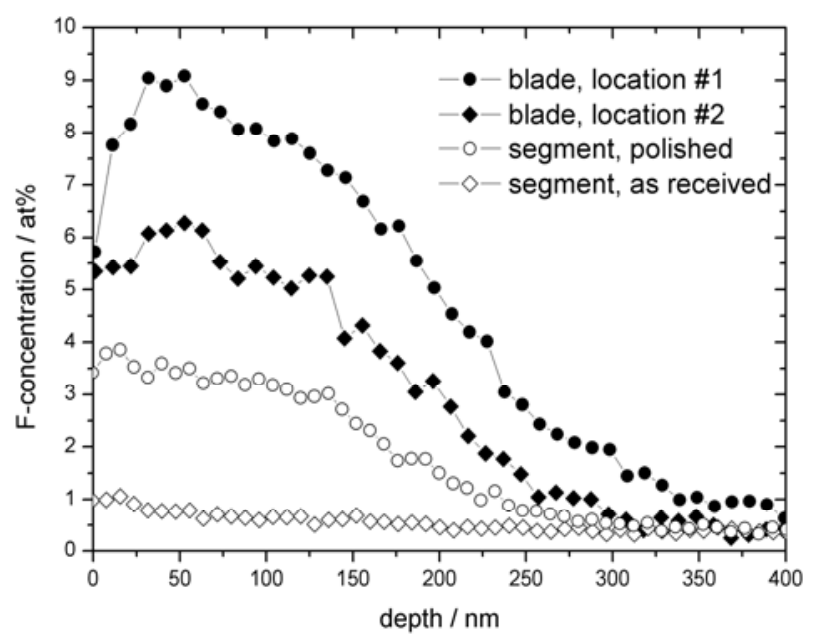

Fig. 5. F-depth profiles on TNB turbine blades with HFtreatment prior to oxidation obtained by PIGE-analysis.

Due to the non-destructive nature of the ion beam analyses used it was possible to detect elemental compositions before and after hightemperature oxidation for $20 \mathrm{~h}$ and additional $100 \mathrm{~h}$ at $900^{\circ} \mathrm{C}$ on the same samples and similar measurement locations.

\section{Analysis prior to oxidation}

The F-profiles of the HF-treated but not oxidized samples were detected with PIGE-analysis and are given in Fig. 5. The profiles of the turbine segments were clearly diffusion controlled with their maximum at the surface. For the uncut turbine blade the F-maximum was found to be in a depth of $40 \mathrm{~nm}$, however. Assuming this blade to have the smoothest surface a strong dependence of the F-content on the surface roughness was recognized.

The detected maximum F-concentrations on locations \#1 and \#2 of the uncut blade (see Fig. 4) differed by about $30 \%$. There was no investigation of the lateral homogeneity of HF-dipping prior to this work. The observed distinction between not even critical places of geometry shows the necessity of this, to optimize the fluorination techniques for real complex components.
For all samples the HF-treatment resulted in maximum F-concentrations lower than 10 at\%. Similar maximum concentrations have been found in laboratory samples using same fluorination parameters [19]. Compared to this, by using beam line ion implantation much higher maximum F-concentrations are achievable ("not oxidized" curve in Fig. 6).

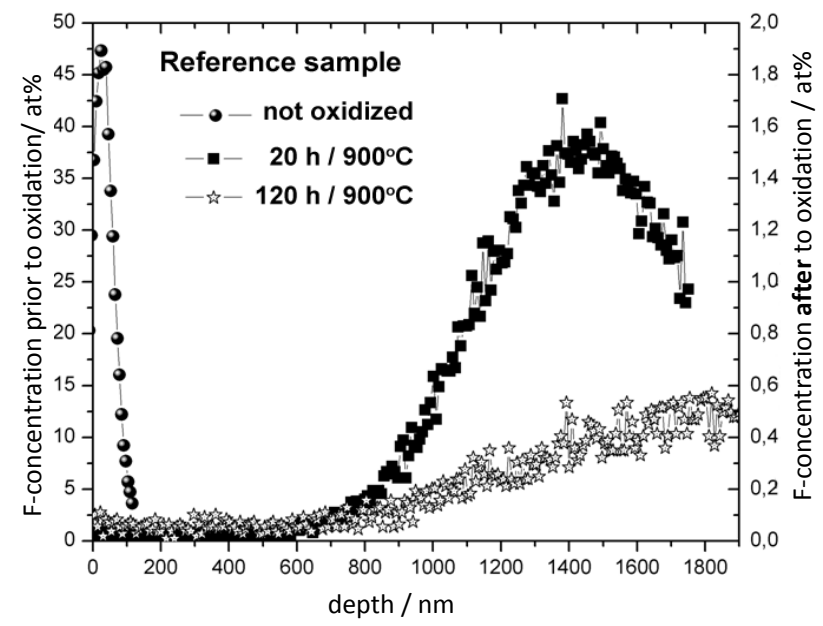

Fig. 6. PIGE-analysis of the beam lne implanted reference sample before and after oxidation.

\section{Analyses after oxidation}

\section{HF-treatment}

After $20 \mathrm{~h}$ oxidation at $900^{\circ} \mathrm{C}$ an approximately $700 \mathrm{~nm}$ thick oxide scale with significantly reduced Ti-concentration was found on the surface of the HF-treated sample. Figures 7 and 8 show elemental depth profiles obtained by RBSanalysis after $20 \mathrm{~h}$ and $120 \mathrm{~h}$ at $900^{\circ} \mathrm{C}$.

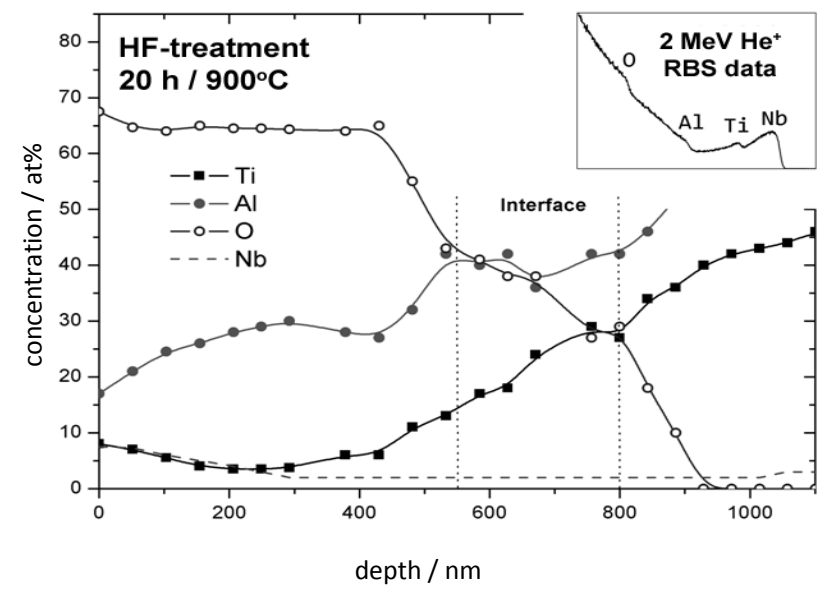

Fig. 7. Elemental depth profiles on a TNB turbine blade with HF-treatment and oxidation for $20 \mathrm{~h}$ at $900^{\circ} \mathrm{C}$ obtained by RBS.

In Figure 7 the scale in a depth of 200-300 nm consisted roughly of $65 \% \mathrm{Al}_{2} \mathrm{O}_{3}, 23 \% \mathrm{TiO}_{2}$ and 
$12 \% \mathrm{Nb}_{2} \mathrm{O}_{5}$, calculated from the elemental concentrations. There was an increased amount of $\mathrm{Nb}$ close to the surface due to preferential dissolution if $\mathrm{Ti}$ and $\mathrm{Al}$ in the acidic solution. The Nb-peak is clearly visible in the RBS-spectra at the top right in the graphs, too.

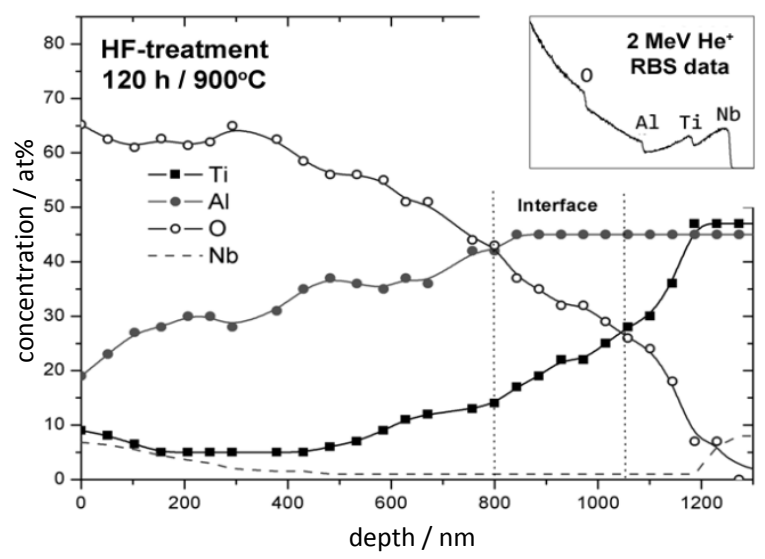

Fig. 8. Elemental depth profiles on a TNB turbine blade with HF-treatment and oxidation for $120 \mathrm{~h}$ at $900^{\circ} \mathrm{C}$ obtained by RBS.

From $20 \mathrm{~h}$ to $120 \mathrm{~h}$ the elemental depthprofiles did not change much. Both spectra showed a decrease in Ti-concentration down to 5 at\% and a drop of the oxygen concentration from approximately 65 at\% at a depth of approximately $400 \mathrm{~nm}$. During the second oxidation step the growth rate of the oxide scale decreased since the passage from oxide scale to the original alloy was found at a depth of $700 \mathrm{~nm}$ after $20 \mathrm{~h}$ and at a depth of $900 \mathrm{~nm}$ after $120 \mathrm{~h}$. Comparing this to the F-profiles obtained by PIGE in Fig. 9 it is apparent that the maximum fluorine concentration is located at the metal/oxide interface below an alumina-rich scale. The detected small F-amounts in this scale are close to the detection limit of the current setup. However, the registered fluorine close to the surface increased to ca. 0.1 at\% during the second oxidation period.

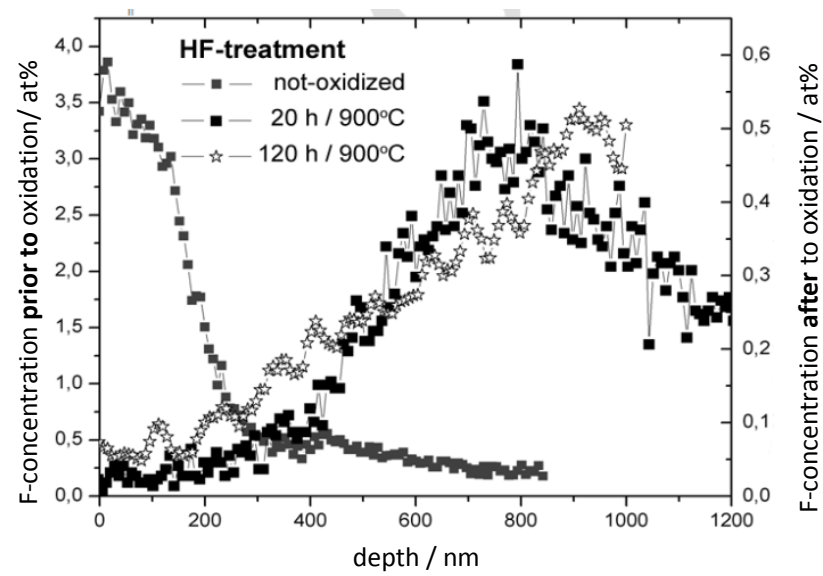

Fig. 9. F-depth profiles on TNB turbine blades before and after oxidation at $900^{\circ} \mathrm{C}$ for $20 \mathrm{~h}$ and $120 \mathrm{~h}$, resp., obtained by PIGEanalysis.

\section{F-aerosol spraying}

In contrast to the HF-treatment the spraying with F-aerosol did not etch the surface during the fluorination process and resulted in almost no $\mathrm{Nb}$ in the whole oxide scale $(0.5 \mathrm{at} \% \mathrm{Nb})$ after oxidation (Figs. 10 and 11). The elemental composition of the scale on this sample differed mainly in terms of $\mathrm{Al}$ - and O-concentrations.

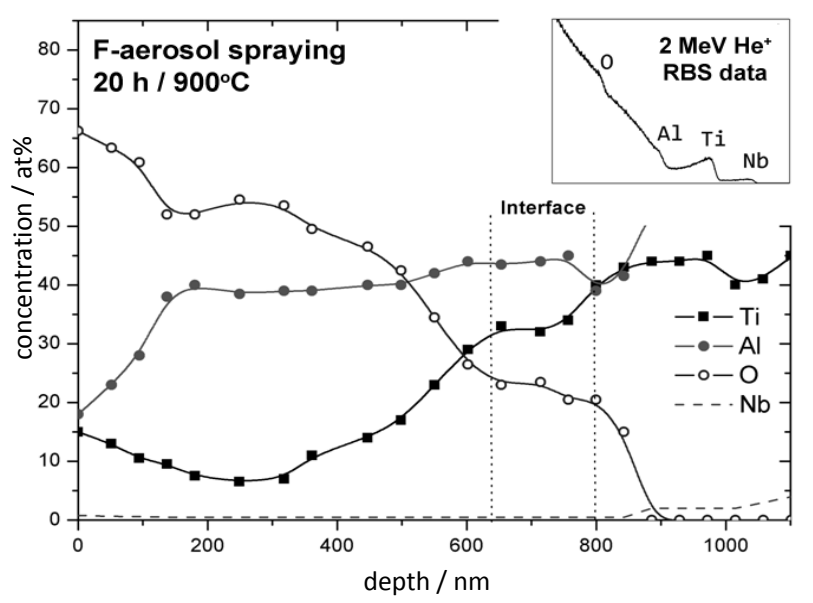

Fig. 10. Elemental depth profiles on a TNB turbine blade with F-aerosol-treatment and oxidation for $20 \mathrm{~h}$ at $900^{\circ} \mathrm{C}$ obtained by RBS.

After $20 \mathrm{~h}$ the oxygen concentration dropped close to the surface, whereas after $120 \mathrm{~h}$ the oxygenprofile is equivalent to that after HF-treatment. In a depth of 200-300 nm a composition of approximately $70 \% \quad \mathrm{Al}_{2} \mathrm{O}_{3}$ and $30 \% \mathrm{TiAl}$ was calculated (Fig. 10). The calculated amounts of TiAl and $\mathrm{TiO}_{2}$ in the scale were caused by a nonhomogenous F-aerosol application as well as a nonhomogenous surface and occur due to the lateral spread of the analyzing beam spot.

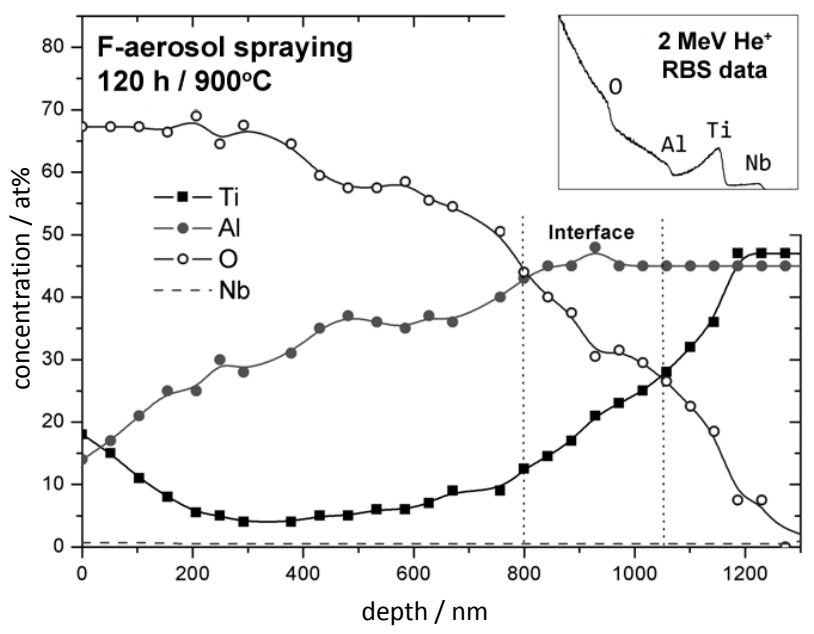

Fig. 11. Elemental depth profiles on a TNB turbine blade with F-aerosol-treatment and oxidation for $120 \mathrm{~h}$ at $900^{\circ} \mathrm{C}$ obtained by RBS. 
Again the growth-rate of the scale decreased in the second oxidation step. F-profiles in Fig. 12 for aerosol treatment were not taken prior to oxidation because the fluorine diffused in the material only during heat treatment. The slightly higher F-concentration after the second oxidation step is probably due to slightly different beam spot locations and/or an inhomogenous F-aerosol application.

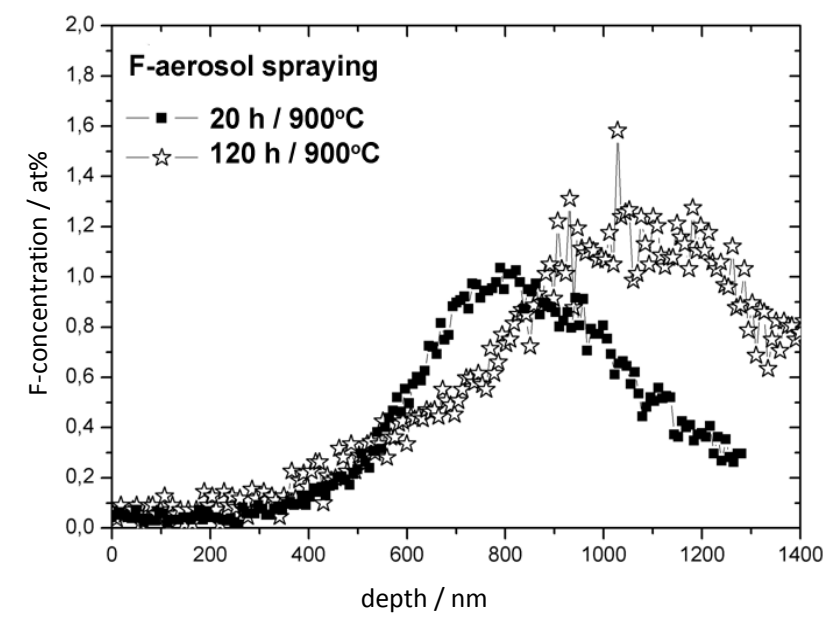

Fig. 12. F-depth profiles on TNB turbine blades after oxidation at $900^{\circ} \mathrm{C}$ for $20 \mathrm{~h}$ and $120 \mathrm{~h}$, resp., obtained by PIGE-analysis.

The depths of maximum F-concentration in Fig. 12 corresponded to the depth of the metal/oxide interface in the Figs. 10 and 11. Just as after HFtreatment a very small amount of fluorine in the range of detection limit was registered close to the surface.

\section{CONCLUSION}

The new vacuum chamber was proven to work and enabled non-destructive recurring ion beam analyses after different oxidation steps on turbine blades or large-scale samples with complex geometries. A laser/camera-system made beam spot observation possible and ensured adequate choice of the measurement place. The time requirement could be reduced by adapting a large sample-holder. An automatically driven HV-bias $(-20 \mathrm{kV}$ to $+35 \mathrm{kV})$ on the sample holder enabled the detection of Fdepth profiles up to a depth of $670 \mathrm{~nm}$ in the TiAlMatrix (470 $\mathrm{nm}$ in the $\mathrm{Al}_{2} \mathrm{O}_{3}$-matrix) without changing the accelerator energy. The depth resolution achieved was approx. $15 \mathrm{~nm}$ close to the surface. Sensitivity for F-detection was about of 0.05 at\%. Quality assurance in industrial-scale was enabled. This is a requirement for implementing $\mathrm{TiAl}$ as new functional material in aircraft engines. The application of TiAl in this high-temperature environment could help saving energy and reducing $\mathrm{CO}_{2}$-emissions by substituting the commonly used Ni-based superalloys which have twice the specific weight.

The unsifficient high-temperature oxidation resistance of the turbine blades with complex geometry was succesfully enhanced by applying two chemical fluorination techniques.

For all samples ion beam analyses indicated the formation of a scale during the first hours of oxidation at $900^{\circ} \mathrm{C}$ which prevented the fluorine from diffusing outwards. Both the material modification by the fluorination processes and the oxidation protection by a thin alumina-rich scale are according to the concept of surface modification with the aim not to worsen the mechanical properties of the bulk material. For all fluorination techniques the thickness of the scale and depth of oxidation interdiffusion was in the range of $1 \mu \mathrm{m}$.

Well-shaped F-profiles with maximum concentrations of 0.5 to 2 at $\%$ could be measured using the non-destructive PIGE-technique. For the chemical treatments the maximum F-concentration and its depth was nearly identical after $20 \mathrm{~h}$ and $120 \mathrm{~h}$ of oxidation at $900^{\circ} \mathrm{C}$. The location of the fluorine at the metal/oxide interface and the formation of an alumina rich scale on top was evidenced by RBS-analysis. Obviously the fluorine was trapped under an alumina scale. However, about 0.1 at\% fluorine were detected after $120 \mathrm{~h}$ close to the surface for all samples.

Etching of $\mathrm{Ti}$ and $\mathrm{Al}$ during the HFfluorination process occurred and caused a Niob concentration in the outer oxide scale in contrast to the F-aerosol treatment. For the HF-treatment the maximum F-content in nonoxidized samples decreased with increasing surface roughness.

\section{ACKNOWLEDGMENT}

The authors gratefully acknowledge the support of the accelerator team around Mr Patrick Ziel at the IKF, University Frankfurt as well as the help of Mr Horst Düring from the Department precision engineering of the University.

\section{REFERENCES}

1. M.T. Jovanovic, B. Dimcic, I. Bobic, S. Zec and V. Maksimovic, J. Materials Processing Technology 167 (2005) 14. 
2. K. Weinert, D. Biermann and S. Bergmann, Annals of the CIRP 56 (2007) 105.

3. E.A. Loria, Intermetallics 8 (2000) 1339.

4. G.H. Meier, Mater. Corros. 47 (1996) 595.

5. A. Rahmel, W.J. Quadakkers and M. Schütze, Mater. Corros. 46 (1995) 271.

6. P.J. Masset, M. Schütze, ECS Trans. 11 (2008) 37.

7. P.J. Masset, S. Neve, H.-E. Zschau and M. Schütze, Mater. Corros. 59 (2008) 609.

8. H.-E. Zschau, V. Gauthier, G. Schumacher, F. Dettenwanger, M. Schütze, H. Baumann, $\mathrm{K}$. Bethge and M. Graham, Oxidation of Metals 59 (2003) 183.

9. H.-E. Zschau, M. Schütze and H. Baumann, K. Bethge, Nuclear Instr. Meth. B 240 (2005) 137.

10. H.-E. Zschau, M. Schütze, H. Baumann and K. Bethge, Nuclear Instr. Meth. B 257 (2007) 383.

11. S. Neve, K. Stiebing, L.Ph.H. Schmidt, H.-E. Zschau, P.J. Masset and M. Schütze, $\begin{array}{llll}\text { Materials } & \text { Science } & \text { Forum } & \mathbf{6 3 8}\end{array}$ (2010) 1384.

12. A. Donchev, B. Gleeson and M. Schütze, Intermetallics 11 (2003) 387.

13. P.J. Masset and M. Schütze, Adv. Eng. Materials 10 (2008).

14. A. Donchev, E. Richter, M. Schütze and R. Yankov, J. of Alloys and Compounds 452 (2008) 7.

15. J.R. Bird, R.A. Brown, D.D. Cohen and J.S. Williams, Ion Beams for Material Analysis, Academic Press (1989) 685.

16. J.F. Ziegler, M.D. Ziegler and J.P. Biersack. Software SRIM 2008: The Stopping and Range of Ions in Matter.

17. M. Mayer, Software SIMNRA 6.04, Max-Planck-Institut für Plasmaphysik, Garching (2008).

18. A. Donchev and M. Schütze, Mater. Corros. 59 (2008) 489.

19. S. Neve, P.J. Masset, R.A. Yankov, A. Kollitsch, H.-E. Zschau and M. Schütze, Nuclear Instr. Meth. B 268 (2010) 3381. 